\title{
Árvores de Baginha (Stryphnodendron guianense (Aubl.) Benth.) em Ecossistemas de Pastagens Cultivadas na Amazônia Ocidental ${ }^{1}$
}

\section{Carlos Mauricio Soares de Andrade ${ }^{2}$, Judson Ferreira Valentim ${ }^{3}$, Jailton da Costa Carneiro ${ }^{4}$}

\begin{abstract}
RESUMO - Foi estudado o efeito de árvores isoladas de baginha (Stryphnodendron guianense (Aubl.) Benth.) sobre alguns aspectos do ecossistema de pastagens cultivadas na Amazônia Ocidental. Avaliaram-se, sob a copa das árvores e na área adjacente a pleno sol, a fertilidade do solo, a serapilheira, o teor de água no solo, a transmissão de luz ao pasto, a disponibilidade de forragem e as composições química e morfológica das gramíneas (mistura de Brachiaria decumbens e B. brizantha cv. Marandu). As árvores de baginha tiveram efeito positivo sobre a fertilidade do solo, notadamente com relação ao conteúdo de matéria orgânica e de nitrogênio, sendo a deposição de grande quantidade de serapilheira, rica em nitrogênio, a principal contribuição. A forragem sombreada apresentou maiores teores de $\mathrm{N}$ e K e menores de $\mathrm{Ca}$, na fração folha verde, do que em áreas a pleno sol. As árvores de baginha apresentaram copa pouco densa, permitindo a transmissão de $27 \%$ da radiação fotossinteticamente ativa incidente ao meio-dia. A elevada cobertura do solo (superior a $85 \%$ ) e a boa disponibilidade de forragem sob a copa da baginha, juntamente com outros atributos, confirmam o potencial desta leguminosa para arborização de pastagens e como componente de outras modalidades de sistemas silvipastoris no trópico úmido.
\end{abstract}

Palavras-chave: arborização, Brachiaria, leguminosa, sistemas silvipastoris, sombra, sustentabilidade

\section{Baginha Trees (Stryphnodendron guianense (Aubl.) Benth.) in Cultivated Pasture Ecosystems in the Western Amazon}

\begin{abstract}
The effect of isolated trees of baginha (Stryphnodendron guianense (Aubl.) Benth.) on some aspects of cultivated pasture ecosystems was studied in the Western Amazon of Brazil. Soil fertility, nutrients in the litter, soil water content, light transmission to sward, herbage availability, and chemical and morphological composition of the grasses (mixture of Brachiaria decumbens and B. brizantha cv. Marandu) were assessed under the canopies of baginha trees and in the adjacent open areas. The trees had positive effect on soil fertility, especially with respect to soil organic matter and nitrogen content, with the great deposition of litter rich in nitrogen being the main contribution. The shaded grass leaves were richer in $\mathrm{N}$ and $\mathrm{K}$, and poorer in Ca, than the unshaded ones. The canopies of the baginha trees presented low density, allowing the transmission of $27 \%$ of the incoming photosynthetically active radiation at noon. The high ground cover (superior to $85 \%$ ) and good herbage availability under the canopies of baginha trees, in addition to other attributes, confirms the potential of this legume as shade tree for pastures and as component of other kinds of silvopastoral systems in the humid tropics.
\end{abstract}

Key Words: shade tree, Brachiaria, legume, silvopastoral systems, sustainability

\section{Introdução}

A formação de pastagens cultivadas na Região Amazônica é realizada, normalmente, pelo sistema tradicional de derruba e queima da floresta, seguido do semeio das forrageiras, quase sempre apenas uma espécie de gramínea. Na maioria dos casos, não há nenhuma preocupação em deixar algumas árvores remanescentes da floresta na área, ou de plantá-las, fato que se deve ao desconhecimento, por parte dos pecuaristas, dos potenciais benefícios que as árvores proporcionam ao ecossistema da pastagem. De fato, muitos pecuaristas consideram indesejável a presença de árvores nas pastagens. Algumas das razões são: a) possibilidade das árvores tornarem-se invasoras ou serem hospedeiras de pragas que atacam o gado ou o pasto; b) haver redução da área útil da pastagem; c) possibilidade das árvores produzirem folhas ou frutos tóxicos para os animais; e d) dificuldade para introdução das árvores nas pastagens. Assim, para incentivar a arborização de pastagens, torna-se necessário identificar espécies que não possuam estas características indesejáveis e que sejam capazes de contribuir positivamente para melhoria do ecossistema da pastagem.

\footnotetext{
${ }^{1}$ Estudo financiado pela Embrapa/CNPq.

2Eng.-Agrôn., M.Sc., Pesquisador da Embrapa Acre, Caixa Postal 321,69908-970, Rio Branco, Acre. E.mail: mauricio@cpafac.embrapa.br

3 Eng.-Agrôn., Ph.D., Pesquisador da Embrapa Acre. E.mail: judson@cpafac.embrapa.br

${ }^{4}$ Zootecnista, D.Sc., Pesquisador da Embrapa Gado de Leite. E.mail: jailton@cnpgl.embrapa.br
} 
Estudos realizados na Região Amazônica (Picollo et al., 1994; Neill et al., 1995, 1997) têm mostrado que ocorre redução significativa das taxas de mineralização líquida de nitrogênio no solo, após a conversão da floresta em pastagens exclusivas de gramíneas. Este fato é um dos principais responsáveis pela queda de produção destas pastagens alguns anos após sua implantação e tem sido atribuído à interação entre a composição química da serapilheira e a mineralização de nitrogênio (N) (Wedin, 1996).

As opções tradicionalmente consideradas para incorporação de $\mathrm{N}$ aos ecossistemas de pastagens cultivadas são a fertilização nitrogenada e a consorciação com leguminosas forrageiras. A fertilização nitrogenada nas pastagens tropicais é pouco difundida, por ser, quase sempre, economicamente inviável, em razão da baixa eficiência e do elevado custo dos fertilizantes nitrogenados e, ainda, do caráter extensivo da exploração das pastagens (Cantarutti \& Boddey, 1997). O uso de leguminosas forrageiras herbáceas, em consorciação com gramíneas, pode proporcionar excelentes resultados, pois, além de fornecer nitrogênio e melhorar o valor nutritivo da gramínea associada, ainda produz forragem de excelente qualidade. No entanto, apesar destas e de outras vantagens do uso de gramíneas e leguminosas herbáceas consorciadas, a persistência destas consorciações tem se mostrado muito difícil, sendo a leguminosa, na maioria das vezes, dominada pela gramínea.

Uma opção pouco considerada para incorporar nitrogênio ao ecossistema da pastagem é a utilização de árvores fixadoras de N. Daccarett \& Blydenstein (1968), avaliando a influência de árvores leguminosas e não-leguminosas sobre as forrageiras que cresciam sob suas copas, verificaram maior conteúdo de nitrogênio total no solo sob as árvores leguminosas, o que se refletia no teor de proteína das forrageiras. Resultados semelhantes foram obtidos por Belsky (1992), no Quênia, por East \& Felker (1993), no Texas, e por Carvalho et al. (1994), em Minas Gerais.

A baginha (Stryphnodendron guianense (Aubl.) Benth.) é uma leguminosa arbórea da família Leguminosae-Mimosoideae, que ocorre de forma espontânea em pastagens cultivadas nos Estados do Acre e Rondônia. Por apresentar copa pouco densa, produzir frutos muito apreciados pelos animais, ser nativa do Trópico Úmido e fixar $\mathrm{N}$ atmosférico (Moreira et al., 1992), apresenta-se promissora para arborização de pastagens e como componente de outras modalidades de sistemas silvipastoris, nesta região.
Para melhor compreensão do efeito de árvores de baginha sobre o ecossistema de pastagens cultivadas na Amazônia Ocidental, foram estudados neste trabalho os seguintes aspectos: fertilidade do solo e ciclagem de nutrientes; teor de água no solo; transmissão de luz através da copa das árvores; e disponibilidade de forragem e composições química e morfológica das gramíneas associadas.

\section{Material e Métodos}

\section{Local de estudo}

Este estudo foi realizado em duas propriedades rurais, localizadas próximas à Vila Nova Califórnia, no Estado de Rondônia. O ecossistema da região é de floresta tropical úmida. A pluviosidade média anual é de $1.900 \mathrm{~mm}$, com estação seca bem definida de julho a setembro, temperatura média anual de $25^{\circ} \mathrm{C}$ e umidade relativa do ar de $87 \%$. O solo dominante é Argissolo Vermelho-Amarelo álico, associado a Latossolo Vermelho-Amarelo álico, com relevo suave ondulado (Lunz et al., 2000).

Em cada propriedade foram estudadas árvores isoladas de baginha (Stryphnodendron guianense (Aubl.) Benth.) que ocorriam nas pastagens, cujo pasto era composto por uma mistura de Brachiaria decumbens e B. brizantha cv. Marandu. De acordo com informações coletadas junto aos proprietários, as pastagens estudadas foram implantadas há, aproximadamente, 12 a 15 anos, e as árvores de baginha surgiram, espontaneamente, nos primeiros anos após o estabelecimento das pastagens. Nas duas propriedades, a densidade arbórea nas pastagens era inferior a cinco árvores por hectare. Por ocasião da realização deste estudo, as árvores estudadas apresentavam, em média, as seguintes dimensões: altura total de 5,3 m; altura da copa de 3,4 m; diâmetro do tronco à altura do peito (DAP) de $24,3 \mathrm{~cm}$; diâmetro da copa de $10,7 \mathrm{~m}$ e área da copa de $90,4 \mathrm{~m}^{2}$. Nas duas propriedades, as pastagens estudadas foram mantidas sob lotação contínua de 1,0 a 1,5 UA/ha, durante todo o ano, sendo o pastejo, em uma delas, realizado exclusivamente por bovinos e, na outra, por bovinos e ovinos conjuntamente.

\section{Delineamento experimental}

As avaliações foram realizadas em setembro de 1997 e em janeiro de 1998. Estudaram-se quatro árvores (consideradas como blocos), no delineamento experimental de blocos ao acaso, com duas repetições 
por árvore, totalizando oito repetições (quatro blocos $\mathrm{x}$ duas repetições por bloco). Foram testados dois tratamentos: a) sombra da baginha, consistindo na área sob sua copa; e b) pleno sol, área fora da influência da copa das árvores (aproximadamente $15 \mathrm{~m}$ de distância). O delineamento de blocos ao acaso foi escolhido para que se pudesse controlar a variação, principalmente de solo, entre as propriedades rurais e cada local dentro da propriedade. Considerou-se que dentro de cada bloco (constituído pela área sob a copa da árvore e adjacente a esta) a variação teria sido induzida pela presença das árvores.

\section{Disponibilidade de forragem}

Em cada avaliação foram coletadas duas amostras da forragem disponível, sob a copa de cada árvore de baginha e na área adjacente a pleno sol, por meio do lançamento de um quadro de madeira com área de $1 \mathrm{~m}^{2}$, e adotando-se altura de corte de $5 \mathrm{~cm}$. Antes do corte avaliaram-se a altura do pasto e a porcentagem de cobertura do solo. A forragem amostrada foi pesada e subdividida em duas subamostras: em uma determinou-se a matéria seca (MS) e a outra foi submetida à separação morfológica em lâmina foliar verde, talo verde (colmo + bainha) e material morto. As amostras da fração lâmina foliar verde foram analisadas quanto aos teores de $\mathrm{N}, \mathrm{P}, \mathrm{K}, \mathrm{Ca}$ e $\mathrm{Mg}$, de acordo com recomendações de Silva (1990). O teor de proteína bruta (PB) foi obtido pela multiplicação do teor de $\mathrm{N}$ pelo fator 6,25 .

\section{Fertilidade do solo e ciclagem de nutrientes}

Após a coleta da forragem disponível, amostrou-se a serapilheira acumulada sob a copa de cada árvore de baginha e na área adjacente a pleno sol, na área útil de $1 \mathrm{~m}^{2}$. As amostras foram pesadas, submetidas à secagem em estufa a $60^{\circ} \mathrm{C}$, por 72 horas, e processadas em moinho tipo "Willey", com peneira de $1 \mathrm{~mm}$. Foram, então, analisadas quanto aos teores de MS, cinzas, N, P, K, Ca, Mg, lignina e celulose, de acordo com recomendações de Silva (1990), e carbono orgânico, conforme metodologia apresentada por Tedesco et al. (1985). Devido à contaminação das amostras com solo, os resultados são apresentados com base na matéria orgânica (MO).

Para avaliação do efeito das árvores de baginha sobre as características químicas do solo, em janeiro de 1998 foram coletadas amostras de solo nas pro- fundidades de 0 a 20 e 20 a $40 \mathrm{~cm}$, em dez pontos sob a copa das árvores e na área adjacente, em cada propriedade. Obteve-se, então, uma amostra composta para cada ambiente (sombra e pleno sol). Estas amostras foram enviadas ao Laboratório de Fertilidade do Solo da Embrapa Acre, sendo submetidas às seguintes análises: $\mathrm{pH}\left(\mathrm{H}_{2} \mathrm{O}\right)$; $\mathrm{P}$ e $\mathrm{K}$ disponíveis; $\mathrm{Al}$, Ca e Mg trocáveis; $\mathrm{H}+\mathrm{Al}$, todas de acordo com recomendações da Embrapa (1979); carbono orgânico e $\mathrm{N}$ total, conforme metodologia apresentada por Tedesco et al. (1985).

Teor de água no solo

O teor de água no solo foi determinado em setembro de 1997 e em janeiro de 1998, de acordo com metodologia descrita pela Embrapa (1979), em amostras de solo coletadas nas profundidades de 0 a $20 \mathrm{~cm}$ (setembro e janeiro) e 20 a $40 \mathrm{~cm}$ (janeiro).

\section{Transmissão de luz através da copa}

Em setembro de 1997, às $13 \mathrm{~h}$ de um dia que se apresentava praticamente sem nebulosidade, determinou-se a transmissão de luz através da copa de duas árvores de baginha, presentes em uma das propriedades. As leituras foram feitas utilizando-se um sensor LI-190SA, acoplado a um medidor de luz LI-1600, ambos da marca LI-COR. Realizaram-se cinco leituras a pleno sol e vinte sob a copa de cada árvore de baginha, a 2,0 $\mathrm{m}$ do tronco e a $40 \mathrm{~cm}$ do solo.

Análise estatística dos dados

Os dados referentes à composição química das folhas verdes da Brachiaria, quantidade de matéria orgânica e de nutrientes acumulados na serapilheira, e altura e teor de MS do pasto, foram submetidos à análise de variância segundo o modelo fatorial, constituído pelos fatores ambiente (sombra e pleno sol) e época do ano (seca e chuvosa), ambos com classificação fixa, utilizando-se o procedimento GLM do programa SAS (Littell et al., 1991), sendo as médias comparadas pelo teste F. Os dados referentes à disponibilidade de forragem e à composição morfológica do pasto foram analisados por estatística descritiva, em virtude de não ter havido controle da utilização do pasto nos períodos que antecederam as avaliações. Não foi feita análise de variância dos dados de cobertura do solo, por não terem atendido ao pressuposto de normalidade, mesmo após serem submetidos à transformação angular. 


\section{Resultados e Discussão}

\section{Fertilidade do solo e ciclagem de nutrientes}

A fertilidade do solo sob a copa da baginha foi, de modo geral, superior à do solo adjacente às árvores, principalmente em sua camada superficial $(0 \mathrm{a} 20 \mathrm{~cm})$, apresentando teores mais elevados de fósforo e potássio disponíveis e de cálcio trocável, maior soma de bases trocáveis (SB) e capacidade de troca de cátions (efetiva, t, e a $\mathrm{pH} 7, \mathrm{~T}$ ), menor teor de alumínio trocável e maiores teores de matéria orgânica (MO) e de nitrogênio total (Tabela 1). Menores teores de $\mathrm{Al}^{3+}$ e maiores de $\mathrm{MO}$ e de $\mathrm{N}$ total também foram observados na camada subsuperficial do solo $(20$ a $40 \mathrm{~cm})$. A complexação do $\mathrm{Al}^{3+}$ pelo húmus (Young, 1997) poderia ser uma das causas dos menores teores de alumínio trocável no solo sob a baginha.

Diversos estudos semelhantes a este (Daccarett \& Blydenstein, 1968; Joffre et al., 1988; Belsky et al., 1989; Oliveira et al., 2000; entre outros), realizados em diferentes regiões do planeta, têm sido consistentes em demonstrar o efeito positivo da presença de árvores sobre a fertilidade do solo, sendo o aumento da matéria orgânica no solo o efeito mais amplamente constatado. São diversas as causas apontadas como responsáveis pela melhoria da fertilidade do solo sob a copa das árvores, entre as quais se destacam: a) deposição de nutrientes absorvidos no subsolo sob a

Tabela 1 - Propriedades químicas do solo sob a copa da baginha e a pleno sol

Table 1 - Chemical properties of the soil under the canopies of baginha and at full sun

\begin{tabular}{|c|c|c|c|c|}
\hline & \multicolumn{2}{|c|}{0 a $20 \mathrm{~cm}$} & \multicolumn{2}{|c|}{$20 \mathrm{a} 40 \mathrm{~cm}$} \\
\hline & $\begin{array}{c}\text { Sombra } \\
\text { Shade }\end{array}$ & $\begin{array}{c}\text { Pleno } \\
\text { sol } \\
\text { Full sun }\end{array}$ & $\begin{array}{c}\text { Sombra } \\
\text { Shade }\end{array}$ & $\begin{array}{c}\text { Pleno } \\
\text { sol } \\
\text { Full sun } \\
\end{array}$ \\
\hline $\mathrm{pH} \mathrm{em} \mathrm{H}_{2} \mathrm{O}(1: 2,5)$ & 4,85 & 5,00 & 4,80 & 4,80 \\
\hline $\mathrm{P}, \mathrm{mg} / \mathrm{dm}^{3}$ & 3,25 & 2,50 & 1,00 & 1,00 \\
\hline $\mathrm{K}, \mathrm{mg} / \mathrm{dm}^{3}$ & 105,50 & 93,25 & 53,67 & 61,25 \\
\hline $\mathrm{Al}^{3+}, \mathrm{cmol}_{\mathrm{c}} / \mathrm{dm}^{3}$ & 0,65 & 0,78 & 1,25 & 1,68 \\
\hline $\mathrm{Ca}^{2+}, \mathrm{cmol}_{\mathrm{c}} / \mathrm{dm}^{3}$ & 2,35 & 1,98 & 0,98 & 0,85 \\
\hline $\mathrm{Mg}^{2+}, \mathrm{cmol}_{\mathrm{c}} / \mathrm{dm}^{3}$ & 0,95 & 0,90 & 0,43 & 0,43 \\
\hline $\mathrm{SB}, \mathrm{cmol}_{\mathrm{c}} / \mathrm{dm}^{3}$ & 3,6 & 3,1 & 1,5 & 1,4 \\
\hline $\mathrm{t}, \mathrm{cmol}_{\mathrm{c}} / \mathrm{dm}^{3}$ & 4,2 & 3,9 & 2,8 & 3,1 \\
\hline $\mathrm{T}, \mathrm{cmol}_{\mathrm{c}} / \mathrm{dm}^{3}$ & 9,5 & 8,1 & 7,0 & 6,4 \\
\hline $\mathrm{V}, \%$ & 37,6 & 38,6 & 21,9 & 22,3 \\
\hline $\mathrm{m}, \%$ & 15,4 & 19,9 & 44,8 & 53,9 \\
\hline M.O., dag/kg & 3,16 & 2,93 & 1,97 & 1,70 \\
\hline $\mathrm{N}$ total, dag/kg & 0,176 & 0,151 & 0,112 & 0,096 \\
\hline
\end{tabular}

copa das árvores ou na área adjacente à copa; b) fixação de $\mathrm{N}$ atmosférico por muitas árvores leguminosas e algumas não-leguminosas; c) elevação da MO do solo, via deposição de serapilheira e decomposição de raízes, com conseqüente aumento de sua capacidade de troca de cátions e de retenção de nutrientes; d) redução da perda de nutrientes por erosão e lixiviação; e) deposição de nutrientes, contidos na água de chuva e na poeira atmosférica, que foram interceptados pela copa das árvores; e f) deposição de nutrientes pela fauna (animais domésticos, pássaros, etc.) que utiliza as árvores como abrigo (Young, 1997).

Na Tabela 2, compara-se a composição química da serapilheira acumulada sob a copa das árvores de baginha com aquela acumulada na área aberta da pastagem. Embora não tenha sido feita separação botânica das amostras, constatou-se que, sob a copa da baginha, a serapilheira era formada principalmente por material orgânico depositado pelas árvores. As maiores diferenças observadas foram quanto aos teores de N, lignina e celulose, mais elevados na serapilheira acumulada sob a baginha. Em virtude do elevado teor de $\mathrm{N}$, a serapilheira da baginha apresentou menores relações $\mathrm{C} / \mathrm{N}$ e celulose/ $\mathrm{N}$. Já a relação lignina/ $\mathrm{N}$ foi menor na serapilheira acumulada na área aberta da pastagem. Os maiores teores de lignina e celulose na serapilheira da baginha devem-se à presença de materiais lenhosos depositados pelas árvores.

De modo geral, a serapilheira acumulada sob a copa da baginha apresentou melhor qualidade que aquela acumulada na área fora de sua influência. $\mathrm{O}$ seu elevado teor de $\mathrm{N}(2,18 \%)$, superior ao valor crítico para que haja mineralização líquida deste nutriente $(1,74 \%$; Palm, 1995), juntamente com as condições microclimáticas normalmente mais favoráveis sob a copa de árvores (Young, 1997), sugerem a existência de maior disponibilidade de $\mathrm{N}$ para as gramíneas crescendo sob a copa da baginha.

$\mathrm{Na}$ literatura não foram encontrados trabalhos avaliando a taxa de decomposição da serapilheira da baginha. Entretanto, Montagnini et al. (1993), comparando a decomposição da serapilheira de quatro espécies arbóreas nativas da Costa Rica, verificaram que a serapilheira produzida pela espécie Stryphnodendron microstachyum foi a que apresentou maior teor de $\mathrm{N}$ e mais rápida decomposição. Montagnini \& Sancho (1994), comparando as taxas de mineralização líquida de $\mathrm{N}$ nos solos sob planta- 
Tabela 2 - Composição química ${ }^{1}$ e índices de qualidade da serapilheira acumulada sob a copa da baginha e a pleno sol (média dos períodos seco e chuvoso)

Table 2 - Chemical composition ${ }^{1}$ and quality indexes of the litter accumulated under the canopies of baginha and at full sun (average of dry and rainy seasons)

\begin{tabular}{|c|c|c|}
\hline & $\begin{array}{l}\text { Sombra } \\
\text { Shade }\end{array}$ & $\begin{array}{l}\text { Pleno sol } \\
\text { Full sun }\end{array}$ \\
\hline Nitrogênio (dag/kg) & 2,18 & 1,23 \\
\hline $\begin{array}{l}\text { Nitrogen } \\
\text { Fósforo }(\mathrm{g} / \mathrm{kg})\end{array}$ & 1,24 & 1,28 \\
\hline $\begin{array}{l}\text { Phosphorus } \\
\text { Potássio }(\mathrm{g} / \mathrm{kg}) \\
\text { Potassium }\end{array}$ & 6,01 & 5,35 \\
\hline $\begin{array}{l}\text { Cálcio }(\mathrm{g} / \mathrm{kg}) \\
\text { Calcium }\end{array}$ & 7,80 & 7,43 \\
\hline $\begin{array}{l}\text { Magnésio (g/kg) } \\
\text { Magnesium }\end{array}$ & 3,93 & 4,03 \\
\hline $\begin{array}{l}\text { Carbono }(\mathrm{dag} / \mathrm{kg}) \\
\text { Carbon }\end{array}$ & 53,40 & 49,50 \\
\hline $\begin{array}{l}\text { Lignina }(\mathrm{dag} / \mathrm{kg}) \\
\text { Lignin }\end{array}$ & 19,45 & 4,90 \\
\hline $\begin{array}{l}\text { Celulose }(\mathrm{dag} / \mathrm{kg}) \\
\text { Cellulose } \\
\text { Índices } \\
\text { Indexes }\end{array}$ & 36,30 & 29,05 \\
\hline $\mathrm{C} / \mathrm{N}$ & 24,60 & 40,50 \\
\hline $\mathrm{C} / \mathrm{P}$ & 437,60 & 390,75 \\
\hline $\begin{array}{l}\text { Lignina/N } \\
\text { Lignin } / N\end{array}$ & 8,90 & 4,00 \\
\hline $\begin{array}{l}\text { Celulose/N } \\
\text { Cellulose/N }\end{array}$ & 16,75 & 23,75 \\
\hline
\end{tabular}

${ }^{1}$ Valores expressos com base na matéria orgânica.

${ }^{1}$ Values expressed on a organic matter basis.

ções de seis espécies arbóreas, também na Costa Rica, constataram maiores taxas de mineralização de $\mathrm{N}$ e de nitrificação, no solo sob as espécies S. microstachyum e Dalbergia tucurensis.

A quantidade de matéria orgânica (MO) acumulada na serapilheira sob a copa da baginha foi, em média, 2,5 vezes superior à existente na área a pleno sol (Tabela 3). Este dado demonstra que as árvores de baginha realizam grande aporte de material orgânico ao ecossistema da pastagem, fator possivelmente responsável pelos maiores teores de MO na camada superficial do solo, sob a copa das árvores (Tabela 1). Boa parte desse aporte de material orgânico ocorre durante o período seco, geralmente no mês de agosto, quando as árvores perdem suas folhas e dispersam seus frutos.

A quantidade de nutrientes (N, P, K, Ca e $\mathrm{Mg}$ ) acumulada na serapilheira sob as árvores também foi superior à da área a pleno sol (Tabela 3), com destaque para o nitrogênio, cuja quantidade foi 4,3 vezes superior à acumulada na serapilheira da área aberta da pastagem. É provável que boa parte do nitrogênio acumulado na serapilheira da baginha seja originário da fixação biológica, representando importante contribuição para o enriquecimento do ecossistema da pastagem com este nutriente, que é um dos principais limitantes à produtividade das pastagens tropicais.

Essa maior quantidade de MO e de nutrientes acumulados na serapilheira pode proporcionar condições para maior atividade biológica no solo sob a copa das árvores (Young, 1997).

Não se constatou interação significativa $(\mathrm{P}>0,05)$ entre ambiente e época do ano e, com exceção do potássio, cuja quantidade acumulada na serapilheira foi maior no período seco que no chuvoso, não houve efeito significativo $(\mathrm{P}>0,05)$ da época do ano sobre a quantidade de $\mathrm{MO}$ e de nutrientes acumulados na serapilheira (Tabela 3). A diferença ocorrida para o $\mathrm{K}$ já era esperada, pois grande parte deste nutriente se encontra em formas livres nos tecidos das plantas, sendo facilmente lixiviado da serapilheira durante o período chuvoso.

Teor de água no solo

No período seco, quando se esperava observar maior umidade no solo sob a copa das árvores, constatou-se que não houve diferença significativa $(\mathrm{P}=0,37)$ entre os ambientes, quanto ao teor de água na camada superficial do solo (Figura 1). A ocorrência de chuvas poucos dias antes da avaliação, provavelmente, foi responsável por esse fato, prejudicando a interpretação do efeito das árvores de baginha na manutenção da umidade do solo no período seco do ano.

No período chuvoso, também não se constatou diferença significativa entre os ambientes quanto ao teor de água no solo (Figura 1), tanto na camada superficial $(\mathrm{P}=0,91)$ quanto na subsuperficial $(\mathrm{P}=0,18)$.

Os resultados obtidos neste trabalho foram insuficientes para esclarecer as relações hídricas existentes na área da pastagem que se encontra sob influência das árvores de baginha.

\section{Transmissão de luz através da copa}

Foi constatado que, em média, $26,7 \%$ da radiação fotossinteticamente ativa (RFA) incidente sobre as árvores de baginha, em horário próximo ao meio-dia, era transmitida através de sua copa. Entretanto, a amplitude das leituras individuais variou de $12,2 \%$ a 
Tabela 3 - Efeito do ambiente e da época do ano sobre a quantidade de matéria orgânica e de nutrientes acumulados na serapilheira

Table 3 - Effect of environment and season on organic matter and nutrients accumulated in the litter layer

\begin{tabular}{|c|c|c|c|c|}
\hline & \multicolumn{2}{|c|}{$\begin{array}{c}\text { Ambiente } \\
\text { Environment }\end{array}$} & \multicolumn{2}{|c|}{$\begin{array}{l}\text { Época } \\
\text { Season }\end{array}$} \\
\hline & $\begin{array}{c}\text { Sombra } \\
\text { Shade }\end{array}$ & $\begin{array}{c}\text { Pleno } \\
\text { sol } \\
\text { Full sun }\end{array}$ & $\begin{array}{l}\text { Seca } \\
\text { Dry }\end{array}$ & $\begin{array}{c}\text { Chuvosa } \\
\text { Rainy }\end{array}$ \\
\hline $\begin{array}{l}\text { Matéria orgânica } \\
\left(\mathrm{g} / \mathrm{m}^{2}\right)\end{array}$ & $607,4^{\mathrm{a}}$ & $250,0^{b}$ & $444,4^{\mathrm{a}}$ & $413,1^{\mathrm{a}}$ \\
\hline $\begin{array}{l}\text { Organic matter } \\
\text { Nitrogênio }\left(\mathrm{g} / \mathrm{m}^{2}\right)\end{array}$ & $13,39^{a}$ & $3,11^{b}$ & $7,77^{\mathrm{a}}$ & $8,73^{\mathrm{a}}$ \\
\hline $\begin{array}{l}\text { Nitrogen } \\
\text { Fósforo }\left(\mathrm{g} / \mathrm{m}^{2}\right)\end{array}$ & $0,69^{a}$ & $0.31^{b}$ & $0.48^{a}$ & 0.53 \\
\hline Phosphorus & & & & 0,5 \\
\hline $\begin{array}{l}\text { Potássio }\left(\mathrm{g} / \mathrm{m}^{2}\right) \\
\text { Potassium }\end{array}$ & $3,37^{\mathrm{a}}$ & $1,34^{\mathrm{b}}$ & $2,71^{\mathrm{a}}$ & $1,99^{b}$ \\
\hline Cálcio $\left(\mathrm{g} / \mathrm{m}^{2}\right)$ & $4,97^{\mathrm{a}}$ & $1,85^{b}$ & $3,48^{\mathrm{a}} \mathrm{a}$ & $3,34^{\mathrm{a}}$ \\
\hline $\begin{array}{l}\text { Calcium } \\
\text { Magnésio }\left(\mathrm{g} / \mathrm{m}^{2}\right) \\
\text { Magnesium }\end{array}$ & $2,35^{\mathrm{a}}$ & $0,98^{\mathrm{b}}$ & $1,65^{\mathrm{a}}$ & $1,68^{\mathrm{a}}$ \\
\hline
\end{tabular}

Médias seguidas de letras distintas, na mesma linha, são diferentes $(P<0,05)$ pelo teste $F$.

Means followed by distinct letters, in the same row, are different $(P<.05)$ by $F$ test.

$72,9 \%$ de pleno sol, demonstrando que a copa das árvores de baginha é pouco densa e permite boa passagem de luz para as forrageiras. Além disso, por se tratar de árvores isoladas, pela manhã e à tarde, quando a altitude solar é menor, a área sob a copa das árvores recebe luz solar direta. Conseqüentemente, as forrageiras que crescem sob a copa das árvores são submetidas a um nível de transmissão de RFA bem superior àquele medido ao meio-dia.

Esta característica de permitir boa transmissão de luz por sua copa é, certamente, um dos fatores que contribuem para a freqüente constatação de bom desenvolvimento das gramíneas que crescem sob esta leguminosa arbórea.

Composição química das lâminas foliares verdes de Brachiaria

Não houve interação entre ambiente e época do ano quanto à composição química das lâminas foliares verdes de Brachiaria, e as plantas crescendo sob a copa da baginha apresentaram maiores teores de proteína bruta $(\mathrm{PB}), \mathrm{N}$ e $\mathrm{K}$, e menores de $\mathrm{Ca}(\mathrm{P}<0,05)$, em suas lâminas foliares, do que aquelas crescendo a pleno sol (Tabela 4). Para os teores de P e Mg não se constataram diferenças significativas $(\mathrm{P}>0,05)$ entre os ambientes. Com relação à época do ano, constataram-se maiores teores de $\mathrm{K}$ e menores de $\mathrm{Mg}$, durante a época seca, em comparação à chuvosa (Tabela 4).

A elevação dos teores de $\mathrm{N}$ e $\mathrm{K}$ na forragem de gramíneas crescendo sob a copa de árvores tem sido freqüentemente relatada na literatura (Belsky, 1992; Carvalho et al., 1997, 1999). Os maiores teores de N na forragem sombreada estão de acordo com a observação, feita durante as amostragens, de que as lâminas foliares das gramíneas sombreadas apresentavam coloração verde-escura intensa, ao passo que as amostras obtidas da área aberta apresentavam-se com coloração verde-clara, indicando deficiência de $\mathrm{N}$ no solo. Estes resultados demonstram que a presença das árvores de baginha nas pastagens, além de contribuir para o aumento da disponibilidade de $\mathrm{N}$ no solo, ainda melhora a qualidade da forragem das gramíneas crescendo sob sua copa, já que o teor de proteína bruta das gramíneas sombreadas foi $50 \%$ maior que o das não-sombreadas (Tabela 4). Entretanto, a constatação de que as gramíneas crescendo na área aberta estavam sofrendo deficiência de $\mathrm{N}$ sugere que a contribuição das árvores estaria restrita à área sob a copa, ou pouco além desta, ou ainda, devido à baixa densidade de árvores nas pastagens estudadas (menos de cinco árvores por hectare), que a contribuição seria muito pequena para conseguir suprir a demanda de $\mathrm{N}$ de todo o ecossistema da pastagem.

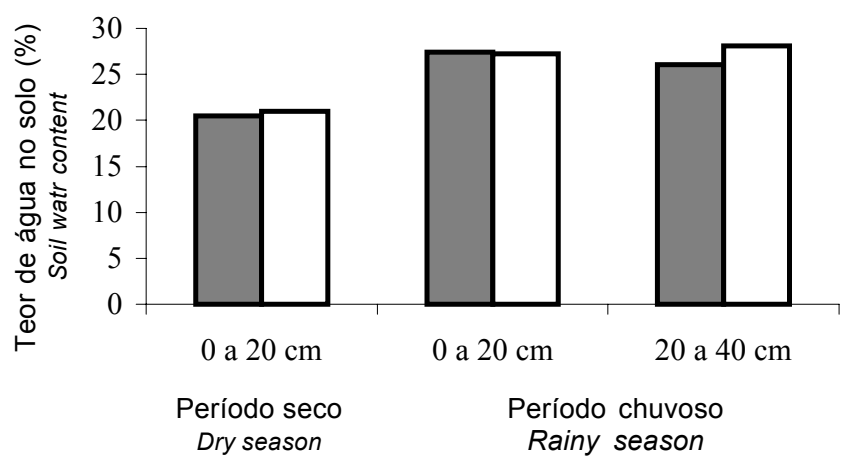

Figura 1 - Teor de água no solo sob a copa da baginha (ם) e a pleno sol ( $\square$ ), nos períodos seco e chuvoso, em função da profundidade.

Figure 1 - Soil water content under the canopies of baginha (घ) and at full sun ( $\square$ ), in the dry and rainy seasons, as a function of the depth. 
Tabela 4 - Efeito do ambiente e da época do ano sobre a composição química das lâminas foliares verdes de Brachiaria spp.

Table 4 - Effect of environment and season on chemical composition of green leaf blades of Brachiaria spp

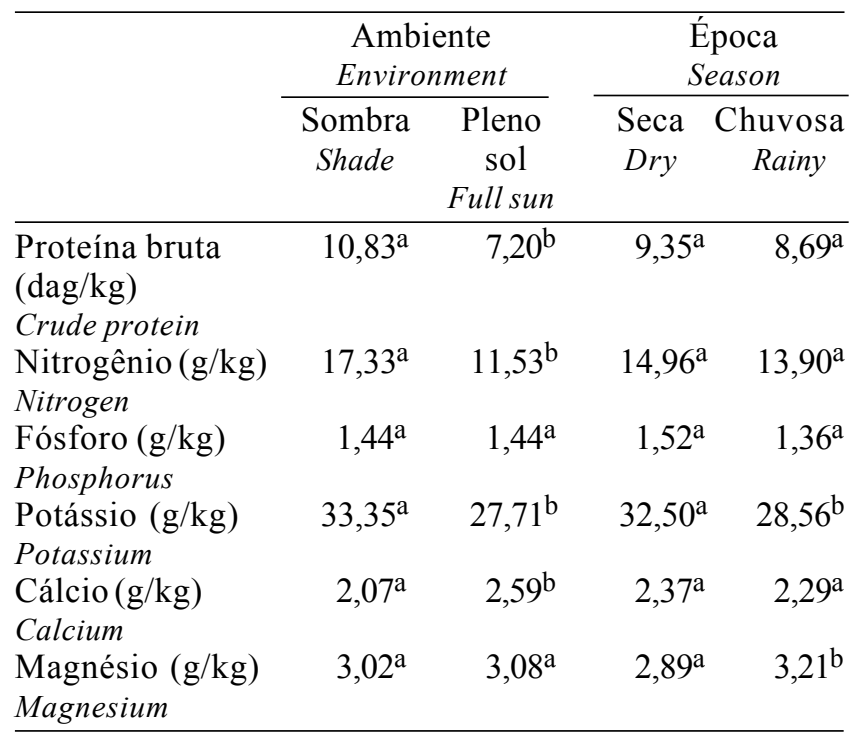

Médias seguidas de letras distintas, na mesma linha, são diferentes $(P<0,05)$ pelo teste $F$.

Means followed by distinct letters, in the same row, are different $(P<.05)$ by $F$ test.

Já a constatação de menores teores de $\mathrm{Ca}$ na forragem sombreada, embora menos freqüente, também tem sido relatada (Carvalho et al., 1994; 1999), possivelmente refletindo menor taxa de amadurecimento das gramíneas sombreadas, já que o cálcio, por ser um nutriente de baixa mobilidade na planta, tende a apresentar maiores teores nos tecidos de folhas mais velhas (Raij, 1991).

\section{Características do pasto}

A disponibilidade de MS total de gramíneas foi menor sob a copa da baginha do que a pleno sol, tanto no período seco quanto no chuvoso (Figura 2). Entretanto, no período seco, essa diferença se deveu principalmente à menor quantidade de material morto presente na forragem sombreada. De fato, nos dois períodos, a quantidade de material morto presente na forragem disponível foi bem maior a pleno sol do que sob a copa da baginha (Figura 2), indicando menor taxa de senescência de folhas para as gramíneas sombreadas.

No período seco, a fração folhas verdes representou apenas $20 \%$ da MS total disponível nos dois ambientes, ao passo que no período chuvoso representou $43 \%$ e $39 \%$, respectivamente, para pleno sol e sombra. Isso se deveu à maior pressão de pastejo

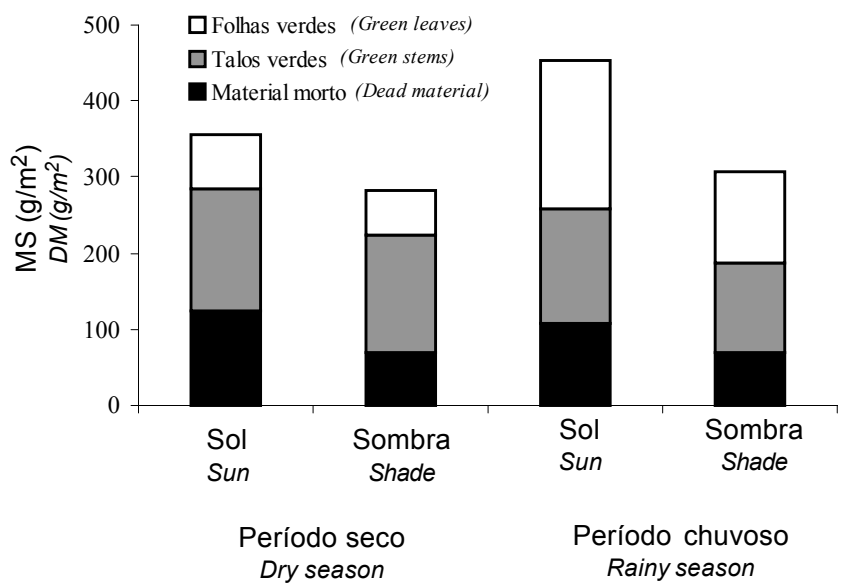

Figura 2 - Composição morfológica do pasto de Brachiaria spp., sob a copa da baginha e a pleno sol, nos períodos seco e chuvoso.

Figure 2 - Morphological composition of the Brachiaria spp. sward, under the canopies of baginha and at full sun, in the dry and rainy seasons.

durante o período seco, já que as pastagens foram utilizadas sob lotação contínua. A menor disponibilidade de folhas verdes no pasto sombreado (Figura 2), maior diferença no período chuvoso, está de acordo com a constatação, feita durante as amostragens, de que as gramíneas sombreadas estavam relativamente mais desfolhadas do que aquelas da área aberta, fato que poderia estar refletindo a maior qualidade (maior teor de PB em suas folhas) e a menor proporção de material morto da forragem sombreada.

No presente estudo, a comparação da disponibilidade de forragem nos dois ambientes ficou prejudicada, em virtude de não ter havido controle da utilização das pastagens pelos animais em pastejo. Sugere-se que sejam realizados estudos para comparar a morfogênese das gramíneas crescendo sob a copa da baginha e a pleno sol, nas duas estações do ano.

As gramíneas crescendo sob a copa da baginha apresentaram menor teor de MS do que as nãosombreadas (Tabela 5). A maior suculência da forragem de gramíneas sombreadas tem sido constantemente relatada na literatura (Norton et al., 1991; Castro, 1996) e pode resultar em maior palatabilidade desta em relação à não-sombreada, principalmente durante o período seco, quando o pasto normalmente se apresenta muito seco (Tabela 5). 
Foi constatado elevado nível de cobertura do solo pelo pasto sob a copa da baginha (Tabela 5), demonstrando, juntamente com a boa disponibilidade de forragem neste ambiente (Figura 2), que as árvores desta leguminosa proporcionam boas condições para o crescimento das forrageiras sob sua copa e, ainda, que sua presença nas pastagens não resulta em redução da área útil destas.

\section{Informações adicionais}

A baginha é muito conhecida na região, principalmente pelos seringueiros e caçadores, porque na época de dispersão dos seus frutos na mata (geralmente em agosto), encontram-se facilmente pacas, cutias, caititus e veados se alimentando deles, que apresentam um cheiro agradável característico. Aliás, o nome comum desta espécie arbórea, baginha, deve-se ao aspecto de seus frutos (pequenas vagens escuras).

Bovinos e ovinos também consomem os frutos que caem das árvores de baginha e, segundo informações coletadas junto aos produtores rurais, não se constatou qualquer sintoma de intoxicação dos animais. Considerando que a época em que ocorre a queda dos frutos da baginha coincide com o período mais crítico do ano, em termos de disponibilidade de forragem nas pastagens da região, dependendo da quantidade de árvores presentes, estas podem ser

Tabela 5 - Efeito do ambiente e da época do ano sobre algumas características do pasto de Brachiaria spp.

Table 5 - Effect of environment and season on some characteristics of the Brachiaria spp. sward

\begin{tabular}{|c|c|c|c|c|}
\hline \multirow[t]{2}{*}{$\begin{array}{l}\text { Características } \\
\text { Characteristics }\end{array}$} & \multicolumn{2}{|c|}{$\begin{array}{l}\text { Ambiente } \\
\text { Environment }\end{array}$} & \multicolumn{2}{|c|}{$\begin{array}{l}\text { Época } \\
\text { Season }\end{array}$} \\
\hline & $\begin{array}{c}\text { Sombra } \\
\text { Shade }\end{array}$ & $\begin{array}{c}\text { Pleno } \\
\text { sol } \\
\text { Full sun }\end{array}$ & $\begin{array}{l}\text { Seca } \\
\text { Dry }\end{array}$ & $\begin{array}{c}\text { Chuvosa } \\
\text { Rainy }\end{array}$ \\
\hline $\begin{array}{l}\text { Teor de MS }(\%) \\
\text { DM content }\end{array}$ & $33,2^{\mathrm{a}}$ & $39,8^{b}$ & $46,1^{\mathrm{a}}$ & $27,0^{\mathrm{b}}$ \\
\hline $\begin{array}{l}\text { Cobertura do } \\
\text { solo }(\%)\end{array}$ & 89,4 & 93,4 & 88,4 & 94,4 \\
\hline $\begin{array}{l}\text { Ground cover } \\
\text { Altura do } \\
\text { pasto (cm) } \\
\text { Sward height }\end{array}$ & $37,1^{\mathrm{a}}$ & $37,7^{\mathrm{a}}$ & $30,7^{\mathrm{a}}$ & $44,2^{b}$ \\
\hline
\end{tabular}

Médias seguidas de letras distintas, na mesma linha, são diferentes $(P<0,05)$ pelo teste $F$.

Means followed by distinct letters, in the same row, are different $(P<.05)$ by $F$ test.

R. Bras. Zootec., v.31, n.2, p.574-582, 2002 importante fonte de alimentos para os animais em pastejo. Na consulta à literatura não foram encontrados estudos sobre a produção e o valor nutritivo dos frutos desta espécie. Com relação às folhas da baginha, parece que não são apreciadas pelos animais, possivelmente devido à presença de algum fator antinutricional, como alto teor de taninos, por exemplo. Este fator pode facilitar o estabelecimento desta espécie nas pastagens.

Um fator indesejável em árvores para sombreamento de pastagens é a presença de raízes superficiais, que atrapalham o conforto dos animais. Nenhuma das árvores de baginha estudadas apresentou esta característica.

Embora as árvores de baginha sejam oriundas de regeneração natural, nos primeiros anos após a implantação das pastagens estudadas, não se constatou a presença de plantas jovens desta espécie em nenhuma das áreas, sugerindo a ausência de caráter invasor desta espécie.

Em toda a Região Amazônica existe grande quantidade de espécies arbóreas que ocorrem espontaneamente nas pastagens, as quais necessitam ser estudadas para identificação de seus atributos e potencialidades. Outra carência a ser suprida é a determinação da densidade arbórea ótima a ser utilizada nas pastagens arborizadas. Com isso, seria possível criar ecossistemas de pastagens mais diversificados e, possivelmente, mais sustentáveis que as atuais monoculturas de gramíneas.

\section{Conclusões}

As árvores de baginha proporcionaram efeito positivo sobre a fertilidade do solo da pastagem, notadamente sobre o conteúdo de matéria orgânica e de nitrogênio. A principal contribuição foi a deposição de grande quantidade de serapilheira, rica em nitrogênio.

A presença de árvores de baginha nas pastagens não reduziu a área útil destas, pois as condições existentes sob sua copa permitiram bom crescimento das gramíneas forrageiras.

\section{Agradecimento}

Aos senhores Antônio Severiano da Silva e Adelmo Cassaro, proprietários das fazendas onde foram conduzidos os estudos, por cooperarem para realização deste trabalho. 


\section{Literatura Citada}

BELSKY, A.J. Effects of trees on nutritional quality of understorey gramineous forage in tropical savannas. Tropical Grasslands, v.26, p.12-20, 1992.

BELSKY, A.J.; AMUNDSON, R.G.; DIXBURY, J.M. et al. The effects of trees on their physical, chemical, and biological environments in a semi-arid savanna in Kenya. Journal of Applied Ecology, v.26, p.1005-1024, 1989.

CANTARUTTI, R.B.; BODDEY, R.M. Transferência de nitrogênio das leguminosas para as gramíneas. In: SIMPÓSIO INTERNACIONAL SOBRE PRODUÇÃO ANIMAL EM PASTEJO, 1997, Viçosa. Anais... Viçosa: Universidade Federal de Viçosa, 1997. p.431-445.

CARVALHO, M.M.; FREITAS, V.P.; ALMEIDA, D.S. et al. Efeito de árvores isoladas sobre a disponibilidade e composição mineral da forragem em pastagens de braquiária. Revista da Sociedade Brasileira de Zootecnia, v.23, n.5, p.709-718, 1994.

CARVAlHO, M.M.; SILVA, J.L.O.; CAMPOS Jr., B.A. Produção de matéria seca e composição química da forragem de seis gramíneas tropicais estabelecidas em um sub-bosque de angico vermelho. Revista Brasileira de Zootecnia, v.26, n.2, p.213-218, 1997.

CARVALHO, M.M.; BARROS, J.C.; XAVIER, D.F. et al. Composición química del forraje de Brachiaria decumbens asociada con tres especies de leguminosas arbóreas. In: SEMINARIO INTERNACIONAL SOBRE SISTEMAS AGROPECUARIOS SOSTENIBLES, 6., 1999, Cali. Memorias... Cali: CIPAV, 1999. 1 CD-ROM.

CASTRO, C.R.T. Tolerância de gramíneas forrageiras tropicais ao sombreamento. Viçosa, MG: Universidade Federal de Viçosa, 1996. 245p. Tese (Doutorado em Zootecnia) - Universidade Federal de Viçosa, 1996.

DACCARETT, M.; BLYDENSTEIN, J. La influencia de árboles leguminosos y no leguminosos sobre el forraje que crece bajo ellos. Turrialba, v.18, n.4, p.405-408, 1968.

EAST, R.M.; FELKER, P. Forage production and quality of 4 perennial grasses grown under and outside canopies of mature Prosopis glandulosa Torr. var. glandulosa (mesquite). Agroforestry Systems, v.22, p.91-110, 1993.

EMPRESA BRASILEIRA DE PESQUISA AGROPECUÁRIA - EMBRAPA. Manual de métodos de análise de solo. Rio de Janeiro, 1979. n.p.

JOFFRE, R.; VACHER, J.; LLANOS, C. et al. The dehesa: an agrosilvopastoral system of the Mediterranean region with special reference to the Sierra Morena area of Spain. Agroforestry Systems, v.6, p.71-96, 1988.

LITTELL, R.C.; FREUND, R.J.; SPECTOR, P.C. SAS ${ }^{\circledR}$ system for linear models. Cary: SAS Institute Inc, 1991. 329p.

LUNZ, A.M.P.; FRANKE, I.L.; SÁ, C.P. et al. Caracterização e avaliação de sistemas agroflorestais na Amazônia Ocidental: Projeto RECA, um estudo de caso. In: CONGRESSO BRASILEIRO DE SISTEMAS AGROFLORESTAIS, 3., 2000, Manaus. Anais... Manaus: EMBRAPA Amazônia Ocidental, 2000. p.349-352.

MONTAGNINI, F.; RAMSTAD, K.; SANCHO, F. Litterfall, litter decomposition and the use of mulch of 4 indigenous tree species in the Atlantic lowlands of Costa Rica. Agroforestry Systems, v.23, n.1, p.39-61, 1993.
MONTAGNINI, F.; SANCHO, F. Net nitrogen mineralization in soils under six indigenous tree species, an abandoned pasture and a secondary forest in the Atlantic lowlands of Costa Rica. Plant and Soil, v.162, p.117-124, 1994.

MOREIRA, F.M.S.; SILVA, M.F.; FARIA, S.M. Occurrence of nodulation in legume species in the Amazon region of Brazil. New Phytologist, v.121, p.563-570, 1992.

NEILL, C.; PICCOLO, M.C.; STEUDLER, P.A. et al. Nitrogen dynamics in soils of forests and active pastures in the western brazilian amazon basin. Soil Biology and Biochemistry, v.27, n.9, p.1167-1175, 1995.

NEILL, C.; PICCOLO, M.C.; CERRI, C.C. et al. Net nitrogen mineralization and net nitrification rates in soils following deforestation for pasture across the southwestern Brazilian Amazon Basin landscape. Oecologia, v.110, p.243-252, 1997.

NORTON, B.W.; WILSON, J.R.; SHELTON, H.M. et al. The effect of shade on forage quality. In: SHELTON, H.M.; STÜR, W.W. (Eds.) Forages for plantation crops. Camberra: ACIAR, 1991. p.83-88.

OLIVEIRA, M.E.; LEITE, L.L.; CASTRO, L.H.R. Influência de árvores de baru (Dipteryx alata) e pequi (Caryocar brasiliense) no solo sob pastagem de braquiária. In: INTERNATIONAL SYMPOSIUM SOIL FUNCTIONING UNDER PASTURES IN INTERTROPICAL AREAS, 2000, Brasília. Proceedings... Brasília: Embrapa Cerrados/IRD, 2000. 1 CD-ROM.

PALM, C.A. Contribution of agroforestry trees to nutrient requirements of intercropped plants. Agroforestry Systems, v.30, p.105-124, 1995.

PICCOLO, M.C.; NEILL, C.; CERRI, C.C. Net nitrogen mineralization and net nitrification along a tropical forest-topasture chronosequence. Plant and Soil, v.162, p.61-70, 1994.

RAIJ, B. Van. Fertilidade do solo e adubação. Piracicaba: Ceres/Potafos, 1991. 343p.

SILVA, D.J. Análise de alimentos: métodos químicos e biológicos. Viçosa, MG: Universidade Federal de Viçosa, 1990. $165 \mathrm{p}$.

TEDESCO, M.J.; VOLKWEISS, S.J.; BOHNEN, H. Análises de solo, plantas e outros materiais. Porto Alegre: Universidade Federal do Rio Grande do Sul, 1985. 188p. (Boletim Técnico de Solos, 5).

WEDIN, D.A. Nutrient cycling in grasslands: an ecologist's perspective. In: JOOST, R.E.; ROBERTS, C.A. (Eds.) Nutrient cycling in forage systems. Columbia: University of Missouri, 1996. p.29-44.

YOUNG, A. Agroforestry for soil management. 2.ed. Wallingford: CAB International/ICRAF, 1997. 320p.

Recebido em: 24/05/01 Aceito em: 10/01/02 